\title{
Estratificação social e usos do tempo \\ Um estudo sobre os indivíduos inseridos no mercado de trabalho*
}

Social stratification and time use

Studying individuals in the labor market

\author{
Luiz Flávio Neubert** \\ Arnaldo Mont'Alvão*** \\ Fernando Tavares****
}

\begin{abstract}
Resumo: A teoria da classe ociosa, de Veblen, vem sendo revista pelos que pretendem compreender a desigualdade social contemporânea e sua relação com o uso do tempo. Atualmente, trabalhadores de alto status despendem longas horas em suas funções e, ao analisar informações sobre uso do tempo da população de uma grande cidade brasileira (Belo Horizonte, MG), encontrou-se a mesma tendência. Ao mesmo tempo, quanto maior o status menor o tempo gasto em atividades de trabalho no fim de semana, e maior o tempo dedicado ao lazer. Enquanto o tempo de trabalho é a base principal sobre a qual se debruçam as desigualdades entre ocupações remuneradas, análises anteriores indicam que as atividades de lazer apresentam altas taxas de participação, independente do período da semana e do status ocupacional. Revisitar a teoria de Veblen permite-nos, então, entender melhor como a estratificação da sociedade se relaciona ao uso do tempo diário.
\end{abstract}

Palavras-chave: Uso do tempo. Desigualdade social. Mercado de trabalho.

Abstract: Veblen's theory of the leisure class has been revisited by scholars looking to understand how social inequalities interact with time use patterns in the contemporary society. They propose to invert Veblen's argument, indicating that higher socioeconomic

\footnotetext{
*Este artigo corresponde a uma adaptação de um trabalho anterior (Neubert, 2006). Difere do original quanto às informações, porque os dados passaram por um segundo processo de correção e atualização, e quanto aos modelos de regressão utilizados.

** Doutor em Sociologia pela Universidade Federal de Minas Gerais (UFMG, Belo Horizonte, MG, Brasil), professor do Departamento de Ciências Sociais da Universidade Federal de Juiz de Fora (UFJF, Juiz de Fora, MG, Brasil)<luizfneubert@yahoo.com.br>.

*** Doutor em Sociologia pela Universidade Federal de Minas Gerais (UFMG, Belo Horizonte, MG, Brasil), professor do Instituto de Estudos Sociais e Políticos da Universidade do Estado do Rio de Janeiro (Iesp/Uerj, Rio de Janeiro, RJ, Brasil)<almontalvao@gmail.com>.

**** Doutor em Sociologia Instituto Universitário de Pesquisas do Rio de Janeiro (Iuperj, Rio de Janeiro, RJ, Brasil), professor do Departamento de Ciências Sociais da Universidade Federal de Juiz de Fora (UFJF, Juiz de Fora, MG, Brasil)<ftavares@caed.ufjf.br>.
} 
status workers tend to spend longer hours in paid work activities. Drawing on data from a time use survey conducted in one of the largest Brazilian cities (Belo Horizonte), we find this same trend. We also found that the higher the socioeconomic status the lower the amount of time dedicated to work in the weekends and the higher the time spend in leisure activities. Whereas work time is the bases upon which inequalities between occupations take place, other analyses indicate that leisure activities show high participation rates, irrespective of the socioeconomic status or the day of the week. Thus, revisiting Veblen's theory equips us to better understand how social stratification is related to daily time use.

Keywords: Time use. Social inequality. Labor market.

\section{Introdução}

Desde Thorstein Veblen (1988), em A teoria da classe ociosa, o tempo recebe atenção especial enquanto objeto sociológico. Estudos contemporâneos têm reinterpretado e conferido novos sentidos e significados do uso do tempo em sociedades complexas. Neste século, pesquisas têm se utilizado das informações sobre os usos tempo para compreender o impacto das mudanças recentes sobre a vida das pessoas. Parte deles deu especial atenção à teoria vebleniana e elaboraram tentativas de atualizar suas proposições (Gershuny, 2005a, 2005b, 2009; Aguiar e Hurst, 2007).

Nesta mesma tradição, este artigo dedica-se a explorar a relação entre dimensões da estratificação social e dos usos do tempo. Mais especificamente, reexamina as desigualdades ocupacionais que incidem sobre o tempo de trabalho remunerado e das diversas atividades de lazer. Como cada sociedade é composta por subgrupos diversos, o exame de como certo agregado de indivíduos utiliza o tempo é de suma importância para se entender como o processo social de produção e reprodução das desigualdades sociais ocorre em diferentes contextos.

\section{O surgimento da classe ociosa}

Uma importante questão de investigação diz respeito à relação que se estabelece entre a dimensão da estratificação social e os usos do tempo. $A$ teoria da classe ociosa (1988), de Thorstein Veblen, pode ser interpretada dessa forma, já que ele examina como determinados grupos sociais vivem e se relacionam com os demais grupos existentes em uma sociedade.

A classe ociosa teria surgido nos estágios mais avançados de uma "cultura bárbara", fundamentada em um modo de vida predatório, baseado na guerra e na caça. A maioria dos membros garantia a sobrevivência do grupo com o 
trabalho diário, liberando alguns membros para a realização de outros tipos de atividades. O desenvolvimento de signos de diferenciação teve início, então, com o surgimento da distinção entre um tipo de trabalho rotineiro, ligado à subsistência, e as atividades que envolviam algum tipo de façanha ou proeza.

Essa diferenciação se deu primeiro entre o que Veblen chamou de "ocupações industriais" e "ocupações honoríficas". ${ }^{1}$ No primeiro grupo de ocupações se enquadra qualquer tipo de trabalho diário e rotineiro, que envolve principalmente as atividades de natureza manual e de subsistência, sendo comumente realizado por escravos, dependentes (criados, empregados etc.) e mulheres, ou seja, membros da classe inferior. O segundo grupo de ocupações corresponde às que não envolvem qualquer tipo de atividade produtiva ligada à subsistência, mas, por outro lado, estão fortemente ligadas à realização de algo especial e que confere honra ao feitor. A guerra, o sacerdócio, a governança e os esportes são atividades típicas deste grupo de ocupações e seriam realizadas predominantemente pelos membros da classe nobre, sacerdotal e seus agregados.

De acordo com o argumento evolucionista de Veblen, o costume e o bom-senso sempre proibiram os membros das classes superiores de exercerem qualquer tipo de atividade ligada à subsistência. Além disso, entre a classe superior (ociosa) e as classes inferiores (produtivas) estão aqueles que exercem as atividades honoríficas "secundárias", as quais também cumprem a função de sustentar materialmente o ócio da classe superior. Desta forma se estabelece a relação entre a dimensão das desigualdades sociais e das atividades cotidianas.

\section{Ócio conspícuo}

As ocupações ligadas à subsistência correspondiam à única atividade pela qual membros das classes inferiores poderiam adquirir algum tipo de posse material. Por outro lado, a força pecuniária das classes superiores se tornava notória aos olhos de todos justamente pelo tipo de atividade oposta, qual seja, o ócio. São atividades que conferem honra e demonstram, portanto, a recusa pública ao trabalho ordinário. $\mathrm{O}$ ócio corresponde, então, às atividades para as quais as classes superiores dedicaram grande parte do seu tempo e que não apresentavam nenhuma utilidade prática ou material imediata.

\footnotetext{
${ }^{1} \mathrm{O}$ termo "industrial", neste contexto, não significa o mesmo que a moderna forma de produção da sociedade industrial. Refere-se a um tipo de trabalho dedicado à subsistência, ou seja, à reprodução pura e simples da sobrevivência. Este tipo de atividade tem como característica principal ser rotineiro, repetitivo e enfadonho, pois não exige nenhum tipo de proeza, criatividade, façanha ou habilidade especial ou talento raro (Gershuny, 2005b).
} 
Porém, o ócio como atividade não-produtiva depende de árdua dedicação e esforço disciplinar no ambiente privado para, depois, se tornar público para os demais membros da classe superior na forma de trejeitos, etiquetas e demonstrações. O conhecimento de línguas mortas e de ciências ocultas, a ortografia correta, a preocupação com o vestuário refinado, com a mobília e a decoração da casa, a participação em jogos e a criação de animais raros são exemplos de atividades não produtivas que envolvem revelam as distinções de comportamento, como a boa educação, polidez, decoro etc. Tudo o que era realizado no ócio, de algum modo, tinha a função de se tornar notório, uma forma de exibição pública dos esforços "não-produtivos", na maneira como estamos designando aqui.

O ócio conspícuo, na concepção de desenvolvimento histórico de Veblen, teve um papel perverso, porém, importante por representar o mais importante signo de honra e demonstração de força pecuniária. Com base no ócio, portanto, os membros das classes superiores viviam sem realizar qualquer tipo de trabalho "produtivo".

\section{As mudanças contemporâneas}

Quando se trata de grupos sociais pequenos, a distinção entre classes superiores e inferiores é facilmente reconhecida por todos os demais através tanto do ócio quanto do consumo conspícuo. Com o desenvolvimento e expansão da diferenciação social, da divisão do trabalho, da vida urbana, do anonimato entre as massas e da mobilidade populacional, o ambiente social se torna cada vez mais vasto e complexo, resultando em mudanças na forma como as "classes" veblenianas se relacionam entre si.

Nesse ínterim, algumas destas tendências devem ser destacadas. A primeira refere-se ao novo foco e reestruturação da relação trabalho/consumo. O desenvolvimento tecnológico desencadeado pela Revolução Industrial na Europa do século 18 gerou um intenso aumento de produtividade econômica. Porém, essa maior eficiência dos meios de produção se converteu em mais tempo de trabalho, em parte direcionado para o consumo conspícuo fortemente incentivado por mensagens publicitárias.

A segunda tendência refere-se ao surgimento do lazer. Somente no processo de nascimento da modernidade é que o ócio foi transformado em tempo livre e, posteriormente, em lazer (Dumazedier, 1975, 1979). Não mais como privilégio de poucos, mas como um direito sucessivamente ampliando desde o século 19 e ao longo do século 20 . O resultado objetivo foi o direito adquirido, inclusive pelos menos abastados, de se tomar parte do tempo livre para a autossatisfação, possibilidade que surgiu juntamente com a instituição 
do individualismo do tipo qualitativo de distinção (Simmel, 2005; Neubert, 2010). A estruturação do lazer está intimamente relacionada, portanto, ao crescimento das atividades de consumo e à expansão das classes médias nas sociedades capitalistas democráticas.

A terceira tendência relaciona as dimensões do consumo e da identidade social. Em ambientes urbanos, marcados pela grande concentração de indivíduos e pelo fluxo incessante de "estranhos", o ócio perde sua capacidade expressiva da força pecuniária de uma classe social. Em meio ao anonimato e à atitude de reserva (Simmel, 1987), o ócio é substituído pelo consumo, o qual, por sua vez, se torna a principal forma de expressão da posição social, honorabilidade e privilégio nas sociedades industrializadas (Veblen, 1988).

A quarta tendência diz respeito à distinção entre as ocupações. A separação entre o trabalho do tipo "produtivo" e a realização de "proezas" e "façanhas" persistiu em meio ao processo de diferenciação e especialização que as ocupações sofreram quando houve a passagem do sistema feudal de produção para o sistema manufatureiro e industrial na Europa. A distinção mais notória que se pode perceber é a divisão entre ocupações manuais (ligadas à rotina das fábricas, repetitivo e de mão-de-obra facilmente substituível) e não-manuais (como as tarefas de administração, supervisão, empreendedorismo, criação e desenvolvimento de tecnologias etc.) (Lipset e Bendix, 1959). A divisão do trabalho social gerou desenvolvimento, elevação da produtividade, expansão e segmentação das classes intermediárias e a consequente multifacetada diversificação de estilos de vida e da organização do cotidiano.

Por fim, as tendências de mudança na composição demográfica das sociedades. Observa-se uma gradativa diminuição no número de filhos que compõem os grupos familiares, o que se converte no aumento e concentração dos gastos individuais em termos de consumo. Esse movimento estrutural, aliado à necessidade crescente de investimento em capital humano entre os mais jovens e ao aumento da longevidade, impossibilitou que as gerações vindouras desfrutassem de algum capital herdado (Gershuny, 2005b).

\section{Uma teoria da classe ociosa revisitada}

Staffan Linder (1970) desenvolveu uma adaptação da teoria da classe ociosa na qual ele previa que alguns indivíduos de sua época se tornariam por demais atarefados com relação às atividades do cotidiano, incluindo o próprio lazer. A este grupo ele deu o nome the harried leisure class. ${ }^{2}$ Ele chegou a tal proposição sobre a alocação do tempo com base nos princípios

\footnotetext{
${ }^{2}$ Algo como "a classe ociosa ocupada", "atarefada" ou "sem tempo".
} 
da microeconomia, seguindo os passos de Gary Becker (1965). Segundo Linder, por causa do grande desenvolvimento econômico experimentado pelas nações mais desenvolvidas economicamente, o tempo de trabalho remunerado aumentou substancialmente em relação ao passado, assim como também a quantidade de bens à disposição para consumo. Como o tempo é, em si, um recurso escasso, ele deve ser alocado de forma "ótima". Assim como ocorre com o tempo de trabalho, o tempo de não-trabalho também deve ter um aproveitamento ótimo, já que os dias têm sempre a mesma duração limitada às 24 horas. De acordo com este argumento, o tempo de não-trabalho (que inclui o lazer) passa a tomar emprestado, do tempo de trabalho, sua forma e características. Por exemplo, o "nível de produtividade" do tempo de nãotrabalho pode ser expandido incrementando-se as atividades de lazer através do consumo de uma quantidade maior de bens, o que é possível graças a longas horas despendidas em atividades de trabalho remunerado. Tragicamente, assim como os trabalhadores fazem seu tempo de trabalho render mais se utilizando de ferramentas, equipamentos e tecnologias, as pessoas passam a consumir certa monta de bens para fazerem com que cada unidade de tempo dedicado ao lazer também seja melhor aproveitada.

Contemporaneamente, outros autores tentaram traçar um panorama atual com base em dados empíricos. A discussão resultou em um importante debate sobre se nas últimas décadas as pessoas têm se dedicado mais ao trabalho (seja remunerado ou não-remunerado, como o trabalho doméstico) ou ao lazer. Ainda, por que muitas pessoas frequentemente têm a sensação de que 24 horas diárias têm sido insuficientes para tantas obrigações e necessidades?

Juliet Schor (1992), em obra que se tornou bem conhecida nos EUA, afirmou que a sociedade norte-americana se dedicava exageradamente ao trabalho na segunda metade do século 20. Diferente do que ocorreu nos países da Europa ocidental à mesma época, o tempo despendido com atividades de trabalho não declinou no período do pós-guerra, e mais, teria ainda sofrido um acréscimo. Contrariamente, o estudo de Robinson e Godbey (1997) apontou que os norte-americanos teriam experimentando mais tempo livre no mesmo período sobre o qual Schor realizara sua investigação. As diferentes interpretações sobre o mesmo cenário, neste caso, podem ter sido consequência do tipo de informação que fora utilizada em cada estudo. Schor se valeu, principalmente, de informações oriundas de censos nacionais, surveys e pesquisas qualitativas. Já Robinson e Godbey se utilizaram de dados oriundos de pesquisas longitudinais sobre os usos do tempo, nas quais se utiliza a técnica de coleta dos "diários" (Aguiar, 2010). 
Igualmente com base em pesquisas de usos do tempo realizadas com cidadãos norte-americanos, Aguiar e Hurst (2007) chegaram a uma conclusão semelhante à de Robinson e Godbey (1997). Descobriram que houve um aumento do tempo de lazer entre a década de sessenta do século passado e o início do século 21, ao passo que o tempo de trabalho remunerado se manteve relativamente estável. Outro achado importante é que esta tendência geral varia fortemente de acordo com o nível de educação formal atingido pelos indivíduos, sendo que o aumento do tempo de lazer foi maior entre os menos educados.

Jonathan Gershuny (2005a, 2005b, 2009) interpretou tal tendência como sendo um sinal de que a correlação entre a classe superior das sociedades modernas contemporâneas e o uso do tempo cotidiano foi "invertida". Com a mudança no conteúdo do status social (a valorização cada vez maior do capital humano nas sociedades modernas) os indivíduos situados no topo da hierarquia social passaram a se dedicar às atividades produtivas (trabalho remunerado, fortemente evitado anteriormente) em detrimento das atividades relacionadas ao ócio. Isso quer dizer que os indivíduos que ostentam as posições mais importantes nas sociedades modernas contemporâneas têm como principal fonte de prestígio social a própria atividade ocupacional que exercem cotidianamente, e não mais as atividades ociosas do passado. Gershuny chamou a este novo grupo de pessoas de superordinate working class. $^{3}$

De forma pioneira, a primeira pesquisa sobre usos do tempo no Brasil, que foi realizada por Amaury de Souza (1976) na capital carioca durante a década de 70, também apresentou um quadro semelhante. Segundo os resultados apresentados, os indivíduos que exerciam ocupações de alto status concentravam mais tempo de trabalho remunerado em dias de semana do que em dias de fim de semana, pois conseguiriam gerar um fluxo de renda que permitisse uma menor dedicação às atividades laborais aos sábados e domingos. Este mesmo fluxo de renda também permitiu pagar por oportunidades de qualificação que garantissem maiores retornos financeiros e por serviços que substituíssem o tempo que seria dedicado aos cuidados com a casa e a família (trabalho doméstico não-remunerado). Além disso, os trabalhadores de alto status puderam garantir um local privilegiado para moradia, o qual permitiria menores gastos de tempo e de dinheiro para deslocamentos pela cidade.

\footnotetext{
${ }^{3}$ Algo como "classe trabalhadora superior".
} 


\section{Aspectos metodológicos}

\section{Fontes de dados}

As análises aqui impetradas tiveram como fonte de informações a Pesquisa de uso do tempo realizada em Belo Horizonte no ano de 2001 (Aguiar, 2010, 2011). As informações sobre as atividades cotidianas ${ }^{4}$ realizadas pelos membros de oitos anos ou mais, de cada domicílio selecionado na amostra, foram registradas em diários de usos do tempo ${ }^{5}$ que foram preenchidos em dois dias especificados, classificados para os objetivos de nossa análise como "um dia de semana" (segunda, terça, quarta, quinta ou sexta-feira) e "um dia de fim de semana" (sábado ou domingo). A caracterização social e demográfica dos indivíduos foi feita com base em informações coletadas através de um questionário socioeconômico.

Para nossa análise foram selecionados indivíduos adultos (18 a 64 anos de idade completos) e ativos no mercado de trabalho, ou seja, apenas aqueles que se declararam como exercendo uma ou mais atividade(s) remunerada(s) nos 30 dias precedentes ao registro da informação. É importante salientar, pois, que foram excluídos do escopo de nossa análise aqueles indivíduos que se declararam como exclusivamente aposentados, estudantes, desempregados ou donas-de-casa.

A tabela 1 apresenta a distribuição de diários preenchidos por sexo e pelo tipo de dia em que o diário foi preenchido. ${ }^{6} \mathrm{O}$ número de casos é muito próximo, sendo que 566 diários foram preenchidos com base em um dia de semana e 582 diários referentes com base em um dia de fim de semana. A proporção de indivíduos por sexo é, respectivamente, $51 \%$ de respondentes masculinos e $49 \%$ respondentes femininos em ambas amostras.

Tabela 1. Proporção de diários preenchidos por sexo

\begin{tabular}{lcc}
\hline \multicolumn{1}{c}{ Sexo } & Dia de semana (\%) & Fim de semana (\%) \\
\hline Masculino & 51 & 51 \\
Feminino & 49 & 49 \\
& $(\mathrm{n}=566)$ & $(\mathrm{n}=582)$ \\
\hline
\end{tabular}

Fonte: Elaboração própria a partir de dados da pesquisa de Usos do tempo em Belo Horizonte (2001). UFMG/CNPq.

\footnotetext{
${ }^{4}$ Foram registradas nos diários de usos do tempo, instrumento que cobre as 24 horas de um dia, as seguintes informações: atividade principal e secundária, horário de início e horário de fim de cada atividade principal, além do local e da companhia em que a mesmo ocorreu.

${ }^{5}$ Questionário em forma de "diário" que apresenta uma régua de tempo, a qual permite que os indivíduos registrem todas as atividades realizadas durante as $24 \mathrm{~h}$ de um mesmo dia.

${ }^{6}$ Apesar de a pesquisa prever que os entrevistados preenchessem os diários para os dois períodos, alguns entrevistados responderam a apenas um deles, o que gera uma ligeira diferença entre o número de diários para cada "tipo" de dia da semana (dia de semana - segunda, terça, quarta, quinta ou sexta-feira - e dia de fim de semana - sábado ou domingo).
} 


\section{Variáveis}

Variáveis dependentes: tempo de trabalho remunerado e de lazer

As atividades registradas nos diários foram classificadas de acordo com dez grandes categorias utilizadas amplamente em surveys de usos do tempo: (a) cuidados pessoais (dormir, comer, lavar-se e vestir-se etc.); (b) trabalho remunerado (trabalho principal com rendimentos, trabalho secundário etc.); (c) estudos; (aulas, estudo em casa, cursos etc.); (d) cuidados com o domicílio e a família (manejo de alimentos, manutenção do domicílio, cuidados com têxteis, compras e serviços, consertos em casa, cuidados com crianças etc.); (e) trabalho voluntário e reuniões (trabalho voluntário, reuniões, atividades religiosas); (f) vida social e atividades culturais (socialização, visitas, namoro, festas, cinema, teatro e concertos, exposições, descanso); (g) esportes e atividades ao ar livre (exercícios físicos, fazer caminhada, correr, jogar bola, pescar etc.); (h) hobbies e jogos (artes, instrumentos musicais, jogos, uso do computador); (i) meios de comunicação de massa (leitura em geral, televisão, rádio, jornal impresso etc.); (j) viagem e uso não especificado de tempo (deslocamento entre as atividades).

Para os propósitos desta análise foram selecionadas o tempo de trabalho remunerado e o tempo de lazer em um dia de semana (segunda, terça, quarta, quinta ou sexta-feira) e em um dia de fim de semana (sábado ou domingo) como variáveis dependentes. O tempo de trabalho remunerado para cada indivíduo foi medido em minutos e calculado através da soma da duração das atividades agrupadas na categoria "b". Já o tempo de lazer foi calculado, também em minutos, através da soma da duração das atividades agrupadas nas categorias "f”, “g”, “h”, “i”, assim como algumas atividades da categoria "e". ${ }^{7}$ Neste caso específico, a seleção das atividades de lazer levou em conta conceitos e definições de Dumazedier (1975; 1979) e Elias e Dunning (1992). ${ }^{8}$

\section{Variáveis Independentes}

Para a dimensão da estratificação social foi utilizado o índice de status socioeconômico (ISSE) ${ }^{9}$ elaborado por Pastore e Silva (2000) para o Brasil.

\footnotetext{
${ }^{7}$ Excluiu-se o tempo gasto em atividades religiosas.

${ }^{8}$ Uma discussão mais densa sobre tal definição pode ser encontrada em Neubert (2010).

${ }^{9}$ A escolha em específico destes critérios de classificação ocupacional decorrem, por sua vez, de escolhas teórico-conceituais dentre alternativas e possibilidades concorrentes para a interpretação do contexto brasileiro (Costa, 2000). Neste caso, a hierarquia de status ocupacional evita certos eixos de diferenciação classista de origem marxista e weberiana para gerar uma métrica a partir de dados empíricos populacionais. A principal crítica a este tipo de artifício é sua perenidade e a não consideração de determinadas dimensões da desigualdade social. Por outro lado, é vastamente utilizado e apresenta a vantagem principal (o que justifica nossa escolha) de transformar a dimensão ocupacional em uma única variável contínua.
} 
Esta escala classifica os indivíduos em uma variável contínua a partir do nível médio de renda e educação das categorias ocupacionais. O ISSE foi utilizado como variável independente nos modelos de regressão, apresentados mais detalhadamente à frente, além de outras variáveis utilizadas nas análises, quais sejam, sexo e idade, as quais cumprem a função de variáveis de controle. ${ }^{10}$

De acordo com a tabela 2, a idade apresenta a mesma amplitude (18-64) em ambas as amostras utilizadas para análise, assim como médias bastante próximas (35/36 anos). O ISSE varia da mesma forma nas duas amostras: vai de 21 a 96 pontos, apresenta média de 48 e desvio padrão de 11 pontos.

O tempo de trabalho remunerado em um dia de semana apresenta média de 421 minutos e desvio-padrão de 231 minutos. Em um dia de fim de semana, para a mesma atividade, a média decresce para 159 minutos e o desvio-padrão é de 239 minutos. Isso demonstra que há muito mais variabilidade para o tempo de trabalho em um dia fim de semana, comparando-se a um dia de semana. O tempo de lazer em um dia de semana apresenta média de 161 e desvio-padrão de 128 minutos, enquanto que em um dia de fim de semana a média aumenta para 342, com desvio-padrão de 209 minutos.

Tabela 2. Estatísticas descritivas das variáveis inclusas nos modelos de regressão

\begin{tabular}{lcccc}
\hline \multicolumn{5}{c}{ Diários preenchidos em um dia semana $(\mathbf{n = 5 6 6})$} \\
\hline & Mínimo & Máximo & Média & Desvio padrão \\
\hline Idade & 18 & 64 & 36 & 11 \\
ISSE & 21 & 96 & 48 & 15 \\
Lazer (min.) & 0 & 900 & 161 & 128 \\
Trabalho (min.) & 0 & 1.050 & 421 & 231 \\
\hline \multicolumn{5}{c}{ Diários preenchidos em um dia de fim de semana (n=582) } \\
\hline Idade & Mínimo & Máximo & Média & Desvio padrão \\
ISSE & 18 & 64 & 35 & 11 \\
Lazer (min.) & 21 & 96 & 48 & 15 \\
Trabalho (min.) & 0 & 1.299 & 342 & 209 \\
\hline
\end{tabular}

Fonte: Elaboração própria a partir de dados da pesquisa de Usos do tempo em Belo Horizonte (2001). UFMG/CNPq.

Obs.: variável categórica 'sexo' é descrita na Tab. 1.

\footnotetext{
${ }^{10} \mathrm{~A}$ literatura dedicada à análise de dados de usos do tempo confirma a necessidade de utilização das variáveis "sexo" e "idade" nos modelos aqui propostos, pois correspondem aos principais fatores de variação sobre a quantidade, qualidade e organização do uso do tempo. Lembramos que neste artigo há um recorte de idade (18-64 anos) que diminui a amplitude da variação desta mesma variável.
} 
A tabela 3 traz os coeficientes de correlação para as variáveis. Observa-se um baixo nível de correlação entre as variáveis independentes, o que diminui as chances de colinearidade. A correlação entre o status socioeconômico e o tempo de trabalho remunerado é levemente positiva para dias de semana $(0,122)$ e levemente negativa para o fim de semana $(-0,121)$. Já a correlação entre o status e o tempo de lazer não é significativa durante a semana, mas é levemente positiva para o fim de semana $(0,119)$.

Tabela 3. Coeficientes de correlação entre as variáveis

\begin{tabular}{lccccc}
\hline & Sexo & ISSE & Idade & $\begin{array}{c}\text { Lazer } \\
\text { dia de semana }\end{array}$ & $\begin{array}{c}\text { Trabalho } \\
\text { remunerado } \\
\text { dia de semana }\end{array}$ \\
\hline Sexo & 1,000 & $0,175^{* *}$ & 0,029 & 0,027 & $0,172^{* *}$ \\
ISSE & $0,175^{* *}$ & 1,000 & $0,100^{*}$ & $-0,056$ & $0,122^{*}$ \\
Idade & 0,029 & $0,100^{*}$ & 1,000 & 0,023 & 0,081 \\
Lazer dia semana & 0,027 & $-0,056$ & 0,023 & 1,000 & $-0,437^{* *}$ \\
$\begin{array}{l}\text { Trabalho remunerado } \\
\text { dia de semana }\end{array}$ & $0,172^{* *}$ & $0,122^{* *}$ & 0,081 & $-0,437^{* *}$ & 1,000 \\
\hline & Sexo & ISSE & Idade & $\begin{array}{c}\text { Lazer } \\
\text { dia fim semana }\end{array}$ & $\begin{array}{c}\text { Trabalho } \\
\text { dia fim semana }\end{array}$ \\
\hline $\begin{array}{lcccc}\text { Sexo } \\
\text { ISSE }\end{array}$ & 1,000 & $0,165^{* *}$ & 0,023 & $0,201 * *$ & 0,038 \\
$\begin{array}{l}\text { Idade } \\
\text { Lazer dia fim semana }\end{array}$ & $0,165^{* *}$ & 1,000 & $0,103^{*}$ & $0,119^{* *}$ & $-0,121^{* *}$ \\
$\begin{array}{l}\text { Trabalho remunerado } \\
\text { dia fim semana }\end{array}$ & 0,023 & $0,103^{*}$ & 1,000 & $-0,006$ &,- 013 \\
\hline
\end{tabular}

Fonte: Elaboração própria a partir de dados da pesquisa de Usos do tempo em Belo Horizonte (2001). UFMG/CNPq.

* sig. $\leq 0,05$ (bilateral); ** sig. $\leq 0,01$ (bilateral)

Obs.: Variável categórica 'sexo': masculino $=1$; feminino $=0$.

- Coeficiente de Pearson (r) foi utilizado para calcular a correlação entre as variáveis 'ISSE', 'Idade', 'Lazer dia de semana', 'Trabalho remunerado dia de semana', 'Lazer dia fim semana', 'Trabalho remunerado dia fim semana' e o Coeficiente Ró de Spearman $(\rho)$ entre a variável ‘Sexo' e as já citadas.

\section{Modelos de regressão de mínimos quadrados ordinários (MQO)}

Para estimar o efeito do status socioeconômico sobre o tempo dedicado ao trabalho remunerado e ao lazer, foram utilizados modelos de regressão de mínimos quadrados ordinários (MQO). Embora existam modelos alternativos, tais como modelos tobit, que também podem ser empregados na análise de dados de usos do tempo, modelos MQO tendem a fornecer coeficientes não 
enviesados para este tipo de análise (Foster, Kalenkoski, 2013; Stewart, 2013) e, por isso, foram escolhidos para as análises dos dados neste estudo. A equação geral para os modelos estimados é a seguinte:

$$
\mathrm{Y}=\alpha+\beta_{1}(\text { indsse } 2)+\beta_{2}(\text { sexo })+\beta_{3}(\text { idade })+\varepsilon
$$

Onde:

$\mathrm{Y}=$ tempo de duração da atividade em um dia (em minutos)

$\alpha=$ constante

$\beta_{i}=$ coeficientes de regressão das variáveis independentes

$\mathrm{X}_{1}=$ índice de status socioeconômico

$\mathrm{X}_{2}=\operatorname{sexo}(0$-feminino; 1 -masculino)

$\mathrm{X}_{3}=$ idade (anos completos)

$\varepsilon=$ erro estocástico

\section{Resultados}

\section{Resultados dos modelos MQO}

As tabelas 4 e 5 apresentam os coeficientes dos modelos de regressão estimando o efeito do status socioeconômico sobre o tempo de trabalho remunerado e sobre o tempo de lazer, respectivamente. O modelo demonstra que o ISSE, controlando-se por sexo e idade, apresenta efeito significativo sobre o tempo de trabalho remunerado em um dia de semana $(\mathrm{p}<0,05)$. A cada elevação de um ponto na escala de status ocupacional há um aumento correspondente de 1,4 minutos sobre o tempo de duração da atividade quando realizada em um dia de semana. Sexo também apresenta efeito significativo, de forma que homens, controlando-se pelo ISSE e pela idade, despendem 69 minutos a mais que mulheres em trabalho remunerado em um dia de semana. Nos fins de semana o efeito do status socioeconômico se inverte, fazendo com que a elevação de cada ponto na escala de status signifique a diminuição de dois minutos no tempo de trabalho remunerado.

No que concerne ao tempo de lazer, os coeficientes indicam que quanto maior o status socioeconômico, maior o tempo dedicado ao lazer nos fins de semana: 1,3 minutos a mais para cada elevação de um ponto na escala de status. Homens, controlando-se pelo status e pela idade, despendem 83 minutos a mais que mulheres em lazer no fim de semana.

Em geral, quanto mais alto o status ocupacional, portanto, mais dedicação ao trabalho remunerado nos dias de semana e mais lazer no fim de semana. Há, também, o efeito negativo sobre o tempo de trabalho remunerado no fim de semana, corroborando a possibilidade de mais lazer neste mesmo período quanto maior for o status ocupacional. 
Tabela 4. Modelos de regressão (MQO) para tempo de trabalho remunerado em um dia de semana e em um dia de fim de semana

\begin{tabular}{|c|c|c|}
\hline \multicolumn{3}{|c|}{ Variável dependente: tempo de trabalho remunerado em um dia de semana } \\
\hline Variáveis independentes & B & Sig. \\
\hline Índice de status socioeconômico & 1,397 & 0,029 \\
\hline Sexo & 68,890 & 0,000 \\
\hline Idade & 1,413 & 0,099 \\
\hline 0,042 & & \\
\hline R2 ajustado & & \\
\hline 566 & & \\
\hline \multicolumn{3}{|c|}{ Variável dependente: tempo de trabalho remunerado em um dia de fim de semana } \\
\hline Variáveis independentes & B & Sig. \\
\hline Índice de status socioeconômico & $-1,983$ & 0,003 \\
\hline Sexo & 19,168 & 0,337 \\
\hline Idade & $-0,450$ & 0,613 \\
\hline 0,017 & & \\
\hline R2 Ajustado & & \\
\hline 582 & & \\
\hline
\end{tabular}

Fonte: Elaboração própria a partir de dados da pesquisa de Usos do uempo em Belo Horizonte (2001). $\mathrm{UFMG} / \mathrm{CNPq}$.

Tabela 5. Modelos de regressão (MQO) para tempo de lazer em um dia de semana e em um dia de fim de semana

\begin{tabular}{|c|c|c|c|}
\hline \multicolumn{4}{|c|}{ Variável dependente: tempo de lazer em um dia de semana } \\
\hline \multicolumn{2}{|c|}{ Variáveis independentes } & B & Sig. \\
\hline \multicolumn{2}{|c|}{ Índice de status socioeconômico } & $-0,596$ & 0,099 \\
\hline \multicolumn{2}{|l|}{ Sexo } & 19,408 & 0,076 \\
\hline \multicolumn{2}{|l|}{ Idade } & 0,320 & 0,509 \\
\hline \multicolumn{2}{|r|}{0,010} & & \\
\hline R2 Ajustado & 0,004 & & \\
\hline $\mathrm{N}$ & 566 & & \\
\hline \multicolumn{4}{|c|}{ Variável dependente: tempo de lazer em um dia de fim de semana } \\
\hline \multicolumn{2}{|c|}{ Variáveis independentes } & B & Sig. \\
\hline \multicolumn{2}{|c|}{ Índice de status socioeconômico } & 1,284 & 0,025 \\
\hline \multicolumn{2}{|l|}{ Sexo } & 82,857 & 0,000 \\
\hline \multicolumn{2}{|l|}{ Idade } & $-0,353$ & 0,643 \\
\hline R2 & 0,053 & & \\
\hline R2 ajustado & 0,048 & & \\
\hline $\mathrm{N}$ & 582 & & \\
\hline
\end{tabular}

Fonte: Elaboração própria a partir de dados da pesquisa de Usos do tempo em Belo Horizonte (2001). UFMG/CNPq. 


\section{Considerações finais}

De forma geral, os resultados confirmam que a dimensão da estratificação ocupacional é fator importante para compreensão de quanto tempo é despendido em atividades de trabalho remunerado e de lazer e da forma como as atividades cotidianas são organizadas entre os diferentes dias da semana. A ocupação do indivíduo apresenta grande influência sobre a organização das atividades ao longo dos sete dias que compõem o período da semana, portanto.

Os resultados também confirmam o pressuposto de que o tempo de trabalho remunerado é a base principal sobre a qual se debruçam as diferenças e as desigualdades entre ocupações remuneradas, o que ocorre de forma bem menos intensa e evidente sobre o tempo lazer. Sobre estas últimas, é importante observar que as taxas de participação são altas, independente do período de tempo examinado (se em dias de semana ou fim de semana) (Neubert, 2013). Isso pode ser interpretado como uma demonstração do fato de que o lazer se afirmou como uma possibilidade ou mesmo um direito em sociedades democráticas contemporâneas de se utilizar parte do tempo cotidiano para a satisfação própria, como já havia registrado Joffre Dumazedier.

A divisão entre dias de semana (segunda a sexta-feira) e dias de fim de semana (sábado e domingo) não é a mesma entre os grupos ocupacionais. Quanto maior o status ocupacional do indivíduo, maior a probabilidade do mesmo ter suas atividades de trabalho remunerado organizadas da forma tradicional, qual seja, trabalho remunerado bastante concentrado em dias de semana e aumento do tempo de lazer no fim de semana. Por sua vez, os indivíduos agrupados nos estratos ocupacionais inferiores experimentam uma fronteira bem mais tênue entre dias de semana e de fim de semana, da mesma forma como já havia atestado Amaury de Souza há décadas atrás.

Os resultados mostram, por fim, que a teoria vebleniana da classe ociosa, em sua versão atualizada, pode ser corroborada: os indivíduos mais valorizados nas sociedades contemporâneas são aqueles mais bem instruídos e intensamente ligados ao mundo do trabalho. Característica importante desse grupo social é a posse de grandes montas de tempo de trabalho remunerado e maior autonomia para organizar o tempo de lazer, apesar de se dedicarem quantitativamente menos a este último grupo de atividades. No entanto, fazem uso de sua capacidade de pecuniária para desfrutar do tempo livre das obrigações em atividades de lazer que garantam a distinção social (Neubert, 2013). 


\section{Referências}

AGUIAR, Mark; HURST, Erik. Measuring trends in leisure: the allocation of time over five decades. Quarterly Journal of Economics, v. 122, n. 3, p. 969-1006, 2007.

AGUIAR, Neuma. Mudanças no uso do tempo na sociedade brasileira. Revista de Ciências Sociais Politica \& Trabalho, n. 34, p. 73-106, 2011.

AGUIAR, Neuma. Metodologias para o levantamento do uso do tempo na vida cotidiana no Brasil. Revista Econômica, v. 12, n. 1, p. 64-82, 2010.

BECKER, Gary. A theory of the allocation of time. The Economic Journal, v. 75, n. 299 , p. $493-517,1965<10.2307 / 2228949>$.

COSTA, Carlos Antônio Ribeiro. Dois estudos de mobilidade social no Brasil. Revista Brasileira de Ciências Sociais, v. 15, n. 44, p. 171-193, 2000.

DUMAZEDIER, Joffre. Questionamento teórico do lazer. Porto Alegre: Ed. Perspectiva, 1975.

DUMAZEDIER, Joffre. Sociologia empírica do lazer. São Paulo: Perspectiva, 1979.

ELIAS, Norbert; DUNNIG, Eric. El ocio en el espectro del tiempo libre. In: Norbert Elias; Eric Dunnig. Deporte y ocio en el proceso de la civilización. Madrid: Fondo de Cultura Económica, 1992. p. 117-156.

FOSTER, Gigi; KALENKOSKI, Charlene. Tobit or OLS? An empirical evaluation under different diary window lengths. Applied Economics, v. 45, n. 20, p. 2994-3010, $2013<10.1080 / 00036846.2012 .690852>$.

GERSHUNY, Jonathan. Veblen in reverse: evidence from the Multinational Time-Use archive. Social Indicators Research, v. 93, n. 1, p. 37-45, $2009<10.1007 /$ s11205-0089369-6>.

GERSHUNY, Jonathan. What do we do in post-industrial society? The nature of work and leisure time in $21^{\mathrm{st}}$ century. Woking papers of the Institute for Social and Economic Research, paper 2005-7. Colchester: University of Essex, 2005a.

GERSHUNY, Jonathan. Busyness as the badge of honour for the new superordinate working class. Woking papers of the Institute for Social and Economic Research, paper 2005-9. Colchester: University of Essex, 2005b.

LINDER, Staffan. The harried leisure class. New York: Columbia University Press, 1970 .

LIPSET, Seymour Martin; BENDIX, Reinhard. Social mobility in industrial society. Los Angeles: University of California Press, 1959.

NEUBERT, Luiz Flávio. Distinções sociais e usos do tempo para lazer. Teoria e Cultura, v. 8, n. 2, p. 102-112,2013.

NEUBERT, Luiz Flávio. Indivíduo, lazer e liberdade na modernidade. Sociedade e Cultura, v. 13, n. 2, p. 277-285, $2010<10.5216 /$ sec.v13i2.13431>.

NEUBERT, Luiz Flávio. Atividades diárias e desigualdade social: um estudo sobre o tempo de lazer e o tempo de trabalho remunerado em Belo Horizonte. Belo Horizonte: Faculdade de Filosofia e Ciências Humanas, Universidade Federal de Minas Gerais, 2006. 90 f. Dissertação de mestrado em Sociologia. 
PASTORE, José; SILVA, Nelson do Valle. Mobilidade social no Brasil. São Paulo: Makron Books, 2000.

ROBINSON, John; GODBEY, Geoffrey. Time for life: the surprising ways Americans use their time. The Pennsylvania State University Press, 1997.

SCHOR, Juliet. The overworked American: the unexpected decline of leisure. New York: Basic Books, 1992.

SIMMEL, Georg. O indivíduo e a liberdade. In. J. Souza e B. Oelze (orgs.). Simmel e a modernidade. 2. ed. Brasília: Editora Unb, 2005. p. 107-115.

SIMMEL, Georg. A metrópole e a vida mental. In: Gilberto Velho (org.). O fenômeno urbano. Rio de Janeiro: Zahar Ed., 1987. p. 11-25.

SOUZA, Amaury de. As 24 horas do dia do carioca. Rio de Janeiro, 1976.

STEWART, Jay. Tobit or not tobit? Journal of Economic and Social Measurement, v. 38 , n. 3, p. $263-290,2013<10.3233 /$ JEM-130376>.

VEBLEN, Thorstein. A teoria da classe ociosa: um estudo econômico das instituições. São Paulo: Nova Cultural, 1988.

Autor correspondente:

Luiz Flávio Neubert

Instituto de Ciências Humanas ( $\mathrm{ICH})$

Campus da Universidade Federal de Juiz de Fora (UFJF)

Rua José Lourenço Kelmer, s/no - São Pedro

36036-900 Juiz de Fora, MG, Brasil

Recebido em: 3 set. 2015

Aprovado em: 27 maio 2016 